\title{
Analyzing Collaborative Patient Care Solutions Using Activity Theory
}

\author{
Fabian Wiser \\ Friedrich Alexander University \\ Erlangen-Nuremberg / \\ Epworth HealthCare \\ fabian.wiser@gmail.com
}

\author{
Carolin Durst \\ Friedrich Alexander University \\ Erlangen-Nuremberg \\ carolin.durst@fau.de
}

\author{
Nilmini Wickramasinghe \\ Epworth HealthCare / \\ Deakin University \\ nilmini.work@gmail.com
}

\begin{abstract}
Collaborative Patient Care Systems have become increasingly popular in the last years as they enable patient-centric quality care delivery to ensue. However, past experiences have shown that technical systems in healthcare are often complex and if not implemented carefully, taking into consideration multiple stakeholder perspectives, they generally fail to realize their full capabilities. Hence, this paper aims to answer, how Activity Theory can facilitate the understanding of the benefits and challenges of a complex technology solution in healthcare. For this purpose, a case study is examined, in which a patient care system, implemented at a hospital in Australia, is mapped to an activity system. Further, problems of the system are uncovered and resolved by the application of an enhanced Activity Theory framework. The study's outcome demonstrates that the introduced framework is an ideal tool to analyze and improve socio-technical systems in healthcare and helps to achieve their full potential.
\end{abstract}

\section{Introduction}

Collaborative Patient Care Systems (CPCS) have received much attention in recent years because they bring new technological possibilities, which hold benefits both for health institutions and patients. CPCS provide on the patient's side entertainment and educational features, while on the clinician's side they offer improved digital communication, computer supported processes, and advanced documentation. Out of these opportunities evolve systems which can enhance the reputation of hospitals and can help them to save costs by improving and streamlining processes [1].

Nevertheless, there exist challenges: CPCS are considered to be complex and critical due to the fact that they deal with human lives. An example of the dangers of using IT in healthcare is the case of the medical electron accelerator Therac-25, which caused several human deaths by massive radiation overdoses [2]. For this reason, it is important to design, develop, and operate systems, bearing in mind the system's risks. Additionally, healthcare systems should not have any flaws which affect the patient's experience or the workflows in health institutions negatively.

In order to prevent such errors and risks, it is suggested to describe CPCS with the social context they are embedded in. This approach has been confirmed as useful in former research [3].

In this paper, we analyze a CPCS, which is in use at a non-for-profit hospital in Australia, in terms of a single case study. To this case study, we apply a theoretical framework, discussed in the next sections, and demonstrate that it is a suitable tool to depict socio-technical systems (STS) in healthcare, as well as disclosing solutions for existing problems in STS.

\section{Background}

"If we focus only on practical usefulness and exclude explanation and interpretation, we do serious harm to our very nature as researcher" [4]. With this statement, Kuutti [4] highlights the key role of theory in activity assessment of Human-Computer Interaction (HCI) systems.

Albeit there are many theories, which try to describe complex actions and matters in information technology, it is a challenge to select the most suitable theory for one's own research purposes.

For instance, Structuration Theory, developed by Giddens [5], explains the interplay between society and the individual. Giddens outlines in his theory that social structures have an impact on human activities, but they also result out of those activities. Essentially the focus of Structuration Theory is to explain how system structures change during time rather than how systems work in particular [6]. The theory is criticized for its high level of abstraction [7] and moreover does not provide descriptive tools to illustrate processes and uncover system problems. This makes it difficult to 
analyze specific HCI systems in detail. Structuration Theory tends to be a useful tool to describe the evolution of a corporate culture than to illustrate specific activities [8].

An alternative to depicting $\mathrm{HCI}$ activities could be the Actor-Network Theory (ANT) created by Latour [9]. This theory places emphasize on the participation of non-human actors in social processes. Hence, a network consists out of several actors, respectively "actants", which can either be a human or a technological entity. ANT has been criticized by Engeström [10] for reducing all actors into "black boxes without identifiable internal systemic properties and contradictions.". In addition, Miettinen [11] raises doubts, that the symmetrical semiotic vocabulary of ANT is not the right concept for describing HCI.

Thus, there is a need for a more operational theory than Actor-Network Theory and Structuration Theory to capture the dynamics of IT in an organization. We proffer Activity Theory (AT) as such a theory [12].

AT differentiates between actors and objects, defines information technology as a mediator and describes the circumstances of activities precisely. This makes it suitable for usage in an HCI context. But we contend it is especially useful for Socio-Technical Systems (which pertain to $\mathrm{HCI}$ ) in healthcare as we shall discuss.

\section{Evolution of Activity Theory}

Activity Theory is a descriptive tool [13] which tries to illustrate human practices and the social context in which they are embedded. The history of AT can be divided into three generations:

First, the Russian psychologist Lev Vygotsky [14] introduced the mediated act. For Vygotsky the interactions between human agents and objects are always connected by a mediating object [14]. This mediator can be a tool, sign or cultural mean. For instance, a radiologist (subject) examines a patient (object) by the help of an MRI (mediating object).

Second, the Soviet developmental psychologist Leontiev [15] extended Vygotsky's theory [14] by the collective notion of activity [16]. He identified that, in order to describe an activity, it is necessary to take account of the community and the social context in which the activity is embedded [15]. Regarding the example described above, the radiologist (subject) examines a patient (object). Throughout the process he is supported by nurses or other assistant doctors (community).

Further, Leontiev [15] outlined the hierarchy of activity. According to him, an activity is driven by a motive and consists out of several actions [15]. These actions are following specific goals and again can be divided into operations [15]. An operation is the smallest entity of the hierarchical structure and depends on the environmental conditions of itself [15].

Lastly, Yrjö Engeström [17] progressed the theories of Vygotsky and Leontiev into an applicable model of systemic structure of human collective activity [18]. Engeström's activity system is still today the most common variant for collective activities and, therefore, lays with Leontiev's hierarchical activity structure the foundation for today's research on AT [19].

Engeström's activity system incorporates subject, object, and community, as well as the mediating objects: tools, rules, and division of labor. All these elements then are transformed into an outcome. Table 1 describes briefly each component of the activity system.

Continuing the example, the radiologist (subject) would examine the patient (object) with the help of MRI (tool), in a hospital setting (community), in which several nurses, doctors and chief physicians work (division of labor). During examination the doctor must stick to general medical ethics and follow the principles of the hospital (rules). When the examination is done, a diagnose protocol is written and the patient gets educated about their results (outcome).

Table 1: Activity Theory - Description of elements [20]

\begin{tabular}{|c|c|}
\hline AT Element & Description \\
\hline Subject & $\begin{array}{l}\text { The subject acts according to its own } \\
\text { motives and goals. It is transforming the } \\
\text { object into a specific outcome. }\end{array}$ \\
\hline Object & $\begin{array}{l}\text { An object can be physical, less tangible } \\
\text { (e.g. a plan) or not tangible at all (e.g. } \\
\text { ideas). The object can alter and evolve } \\
\text { during the activity is performed. }\end{array}$ \\
\hline Community & $\begin{array}{l}\text { The community is the group or team in } \\
\text { which the subject is performing the } \\
\text { activity. It also includes persons who take } \\
\text { an interest in the activity (stakeholders). }\end{array}$ \\
\hline Tools & $\begin{array}{l}\text { Tools mediate the relationship between } \\
\text { subjects and objects. They can be of both } \\
\text { physical (e.g. computers) and non-material } \\
\text { nature (e.g. software, language). }\end{array}$ \\
\hline Rules & $\begin{array}{l}\text { Rules are explicit as well as tacit laws, } \\
\text { norms, conventions and expectations. They } \\
\text { determine the interaction between subject } \\
\text { and its community. }\end{array}$ \\
\hline $\begin{array}{l}\text { Division of } \\
\text { Labor }\end{array}$ & $\begin{array}{l}\text { The definition of labor defines implicitly } \\
\text { and explicitly the roles and hierarchy of the } \\
\text { community with regards to the object. }\end{array}$ \\
\hline Outcome & $\begin{array}{l}\text { The outcome is the modified and altered } \\
\text { object after the execution of the activity. }\end{array}$ \\
\hline
\end{tabular}




\section{Contradictions in Activity Theory}

Due to the fact that activities continuously evolve and alter, they are fundamentally marked by contradictions [16]. Contradictions are "historically accumulating structural tensions within and between activity systems"[21]. Engeström notes that they are a crucial factor for innovation and human learning [17]. Moreover, he explains that there are four key kinds of contradictions in AT [17]:

First-level contradictions are contradictions which appear inside of a component. E.g. the existence of a conflict between rules.

Second-level contradictions occur between two components, such as subjects not complying given rules.

Third-level contradictions describe potential problems caused by the relation between an existing activity system and its more evolved object or outcome [22]. There can be resistance to alter and update an existing system.

Fourth-level contradictions refer to tensions in the network of neighboring activity systems. Whenever components or results are part of more than two activities a conflict can occur.

\section{An Activity Theory based Framework}

According to Bedny [23], traditional AT is a complex and time consuming approach for research. It is for this reason that AT has been criticized as being "not a dead horse, but maybe a sleeping one" [12]. However, AT has contributed to the transformation of $\mathrm{HCI}$ and established itself as a major factor in the research of HCI [19]. Hence, Luber [24] analyzed the main disadvantages of AT with regards to Computer Supported Cooperative Work, which is a subgroup of HCI. These disadvantages were found by out carrying a literature review and sorting the results into different problem areas. Furthermore, a framework was developed, which intends to solve these problem areas. The framework provides a Microsoft Excel workbook and a process chart that should help future researchers to understand and apply the AT based framework. The framework is split into three phases: System Overview, System Analysis, and System Improvement [24]. These stages are going to be explained next, after introducing the seven identified problem areas (see Table 2).
Table 2: Problem areas of Activity Theory [24]

\begin{tabular}{|l|l|}
\hline Problem Area & Problem Description \\
\hline Flexibility & $\begin{array}{l}\text { Results out of the application of AT are not } \\
\text { comparable. Researchers tend to interpret } \\
\text { the theory differently. }\end{array}$ \\
\hline Terminology & $\begin{array}{l}\text { Misunderstanding between the two terms } \\
\text { 'object' and 'objective'. AT terms are } \\
\text { unknown to newcomers. }\end{array}$ \\
\hline Documentation & $\begin{array}{l}\text { A standardization of AT is missing. There is } \\
\text { no explanation how to document } \\
\text { contradictions and recommendations for } \\
\text { solving tensions in the activity system. }\end{array}$ \\
\hline Vertical nature & $\begin{array}{l}\text { Most of the time, AT application does not } \\
\text { take Leontiev's hierarchy system into } \\
\text { consideration [15]. }\end{array}$ \\
\hline Horizontal nature & $\begin{array}{l}\text { By describing an activity system, it is also } \\
\text { important to illustrate the connection to } \\
\text { neighboring activities. }\end{array}$ \\
\hline Contradictions & $\begin{array}{l}\text { System tensions are not uniformly captured. } \\
\text { A classification into the four different levels } \\
\text { does not take place in many cases. }\end{array}$ \\
\hline Improvement & $\begin{array}{l}\text { A procedure for developing } \\
\text { recommendations out of contradictions is } \\
\text { missing. }\end{array}$ \\
\hline
\end{tabular}

(1) In the System Overview phase the practitioner creates the whole activity system by ignoring vertical and horizontal aspects of Activity Theory.

By providing a structured process with standardized tasks, researchers can compare their results. Thus, the stated problems regarding flexibility and documentation are solved. Furthermore, researchers who are new in the field only have to read the provided introductory guide for the application relevant information of Activity Theory in order to understand the theory's concepts. Consequently, the problem of correct terminology no longer exists.

(2) During the System Analysis phase the holistic activity is broken down into sub-activity systems, representing the consecutive process steps of the entire activity. The vertical and horizontal nature of Activity Theory is in focus [20].

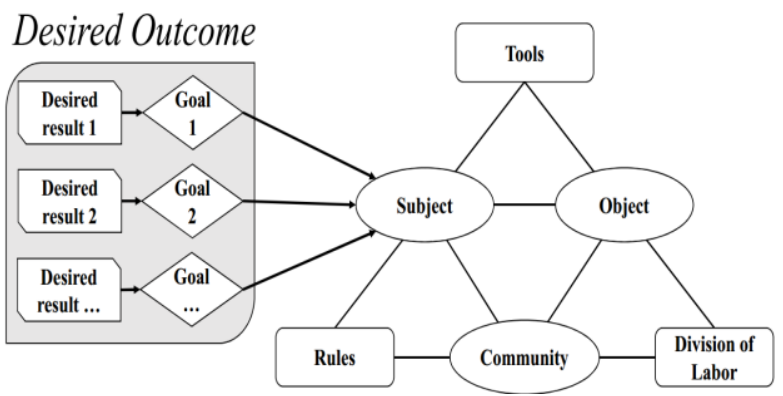

Figure 1: Luber's activity model [24] 
Other than in Engeström's model [17], the (desired) outcome is set as starting point of the (sub-) activity systems in the framework, following suggestions of Bedny [23] (see Figure 1). Furthermore, the desired outcome is decomposed into goals and their corresponding desired result. Goals constitute the improvement parameters of the system.

(3) The System Improvement phase is divided into two processes:

As a first step, all contradictions of the whole activity system, including all its sub-activities, are documented and categorized.

Afterwards, encountered tensions are resolved by the means of TRIZ and solutions are noted within the framework. TRIZ stands for the Russian acronym of "Theory of Inventive Problem Solving". The theory was invented by the Russian engineer Gerich Altshuller and provides a systematic problem-solving tool [25]. For the sake of the AT framework, TRIZ has been slightly amended (see Figure 2).

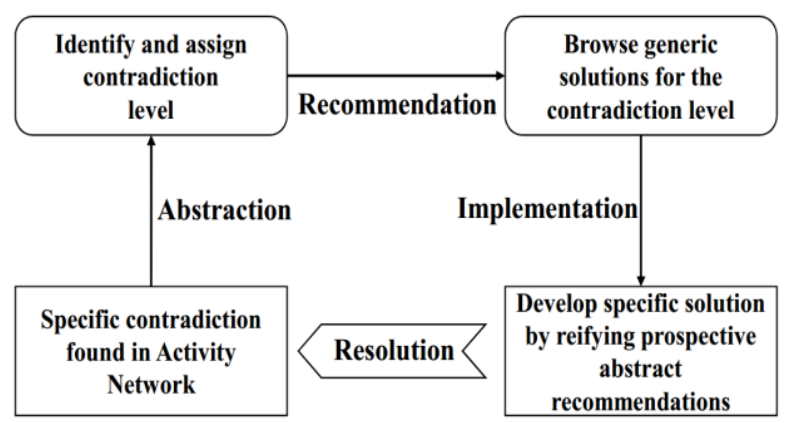

Figure 2: Procedure of solving a contradiction with TRIZ [24]

By categorizing tensions and applying TRIZ the workbook tries to solve the stated problems regarding system contradictions and improvement.

\section{Activity Theory in Healthcare}

In the last years only few research on activity theory in a healthcare context has been undertaken. However, these studies have shown that AT is an appropriate tool to depict complex medical settings:

Riechert [3] applied AT to describe a chemotherapy ordering process in a non-for-profit hospital in Australia. She conducted a qualitative research, gathering data from specific studies, literature, and a case study [3]. Due to the fact that chemotherapy ordering is a major aspect of cancer treatment and is deemed to imply high risks, AT was elected as a "robust and rich lens" [3] to analyze success factors of the implementation process of a computerized physician order entry system. Therefore, the adaptive mapping process of Wickramasinghe et al. [26] was applied with a view to gain insight on the activity system of the ordering process. As a result, eleven tensions within the ordering procedure were uncovered. In conclusion, it was disclosed that AT is a proper theory to describe complex healthcare systems, because AT illustrates precisely the interactions and partnerships between the medical stakeholders of a process (doctors, nurses, etc.); AT helps to overcome barriers in healthcare and to provide best possible results for healthcare.

In another study of Engeström [27], AT was applied to depict the process of medical assessment of small children including their referral between hospitals and medical specialists. In this respect AT helped to encounter contradictions between the different healthcare institutions and to support practitioners to focus on the main causes of existing problems.

Coleman [28] described the readiness of using modern eHealth tools in South African health clinics. According to Coleman, this readiness can be divided into four subgroups with regards to the elements of AT: Need-change readiness for subjects, engagement readiness for objects, technological readiness for tools, and societal readiness for the community [28]. The findings of the study led to the suggestion that Engeström's activity system [17] is a perfect framework to assess eHealth readiness [28].

As can be seen from literature, AT is a useful theoretical framework which helps to understand healthcare processes and their inherent problems [3] [27][28]. Yet it has not been applied on modern healthcare technologies, like a CPCS - introduced in the next section -, nor has an AT software been used to depict a healthcare activity system, revealing contradictions and providing standardized solutions.

\section{Collaborative Patient Care Systems}

Collaborative Patient Care Systems (CPCS) support the healthcare process by providing educational and entertainment resources for patients, communication channels between professionals and patients, as well as access to medical record systems [29]. In many cases they also feature solutions for the integration of existing hospital systems and workflow management. CPCS are distributed socio-technical systems with user-interfaces for patients in the form of bedside touch monitors and for clinicians and healthcare administration staff in terms of workstations and mobile devices.

CPCS offer many advantages, such as an increased patient experience, reduced errors by unreadable orders in computerized provider entry systems and improvement of communication [29]; apart from that, 
they can shorten the length of stay for patients and, therefore, reduce costs for hospitals [30]. Summing up one can say that the implementation of an CPCS is always fulfilled with the intention of improving healthcare processes.

However, CPCS contain risks both on the operational and technical level. For instance, clinicians can trust the implemented system more than it is called for [29]. Moreover, the realization of CPCS can in some cases imply cumbersome and busier workloads, for the sake of process alignment [29]. Direct efficient communication between parties could also be prevented by filling out forms instead of talking [29]. Last but not least, besides coding errors and bugs in the software, the system could have flaws regarding its design, which cause problems during operation[29].

Nevertheless, CPCS offer a great chance to improve and revolutionize healthcare industry. For this reason we want to apply an AT framework on the CPCS of a non-for-profit hospital situated in Australia, uncovering and resolving contradictions in order to make the system a success for the hospital, clinicians, and patients.

\section{Methodology}

The current investigation involves a qualitative research approach to answer the research question: "How can AT facilitate the understanding of the benefits and challenges of a complex technology solution in a healthcare context?"

A case study methodology is followed because this study investigates a "how" research question, focused on a new evolving area with current relevance (i.e. contemporary events) and relevant behaviors cannot be manipulated directly, precisely and systematically by the researcher [31]. Hence, the case study approach is the appropriate method for conducting this research [31].

In conducting the explorative single case study, data was collected from the extant literature, archival records, interviews with key informants, and direct observations. The literature review and the archival records were critically evaluated and this assisted in developing an understanding of the general workflow processes executed in the hospital under study. Recognized techniques of thematic analysis were applied to the interview data [32]. The interview data was transcribed by one person and checked by another researcher to ensure a high level of data accuracy while data validity was achieved using triangulation [33]. This analyzed interview data provided information about the infrastructure and implementation of the CPCS in the health institution and its various establishments. Direct observations were made during a workshop, introducing the technology and software features of the CPCS.

The AT workbook (see section 5) was completed by using the accumulated data in order to depict the whole activity system in detail, as well as uncovering contradictions and finding solutions for tensions.

\section{Application of the AT Framework}

The activity under investigation is the workflow management of the CPCS "OneView Point of Care", henceforth referenced as PoC. Corresponding to section 5, this case study is divided into System Overview, System Analysis, and System Improvement.

\subsection{System Overview}

The PoC provides several services for the hospital under research. There is an entertainment feature for patients, providing movies, audio books, music, and games on the bedside screen. Moreover, the patient can invoke relevant educational documents for their medical treatment and order their food on screen.

Nevertheless, in our study, we want to focus on the clinician's side of the PoC, which is the workflow management (WM), because examining all available services would make the study too large.

The WM as an entire activity is composed out of four sub-activities: Room Ready, Admission Survey, Leader Rounding, and Nurse Rounding (see Table 3 for a brief description). The subjects of the activity system of WM are nurses as well as nonclinical staff for cleaning. The object is the patient, which has to be treated by the means of the PoC. The overall desired outcome of the activity is the healthy and satisfied patient.

Table 3: Sub-activities of workflow management

\begin{tabular}{|l|l|}
\hline $\begin{array}{l}\text { Sub-activities } \\
\text { of WM }\end{array}$ & Brief description \\
\hline Room Ready & $\begin{array}{l}\text { The process required to ensure that the room } \\
\text { is operational for new patients. }\end{array}$ \\
\hline $\begin{array}{l}\text { Admission } \\
\text { Survey }\end{array}$ & A survey to capture the key patient items. \\
\hline $\begin{array}{l}\text { Leader } \\
\text { Rounding }\end{array}$ & $\begin{array}{l}\text { Conducted at regular time intervals to verify } \\
\text { that all open issues have been addressed and } \\
\text { patients are tracking as expected. }\end{array}$ \\
\hline $\begin{array}{l}\text { Nurse } \\
\text { Rounding }\end{array}$ & $\begin{array}{l}\text { Conducted regularly to ensure that patient } \\
\text { vital signs, medications and other critical } \\
\text { aspects of their care are all under control. }\end{array}$ \\
\hline
\end{tabular}

Now that the overall activity system is defined, the sub-activities can be examined thoroughly in the System Analysis. 


\subsection{System Analysis}

As the first step of the System Analysis, all goals of the holistic activity system have to be defined. The goals of WM are described in Table 4. Goals help to understand the purpose of the sub-activities and, consequently, assist the researcher finding contradictions [24].

Table 4: Goals of workflow management [1]

\begin{tabular}{|l|l|}
\hline WM-Goal & Description \\
\hline Cost savings & $\begin{array}{l}\text { The hospital saves costs by using the PoC } \\
\text { system by implementing streamlined } \\
\text { processes. }\end{array}$ \\
\hline $\begin{array}{l}\text { Focus on } \\
\text { priority actions }\end{array}$ & $\begin{array}{l}\text { Processes are aligned towards the surveys } \\
\text { clinicians have to fill out. For this reason, } \\
\text { they can concentrate on their primary task. }\end{array}$ \\
\hline $\begin{array}{l}\text { Customer } \\
\text { experience }\end{array}$ & $\begin{array}{l}\text { Increased convenience for patients and } \\
\text { clinicians providing an easy to use platform. }\end{array}$ \\
\hline Health risks & $\begin{array}{l}\text { The risks for patients to fall or to get served } \\
\text { improper food is lowered. }\end{array}$ \\
\hline Staff hours & $\begin{array}{l}\text { The PoC system optimizes workflows. This } \\
\text { optimizaton leads to a reduction of working } \\
\text { hours. }\end{array}$ \\
\hline $\begin{array}{l}\text { Bed occupancy } \\
\text { rate }\end{array}$ & $\begin{array}{l}\text { Improved bed-occupancy rates and service } \\
\text { quality provided by facility employees. }\end{array}$ \\
\hline $\begin{array}{l}\text { Call light } \\
\text { usage }\end{array}$ & $\begin{array}{l}\text { The usage of the call light button decreases } \\
\text { due to the regular assistance of nurses. }\end{array}$ \\
\hline Food waste & $\begin{array}{l}\text { Nurses can change the diet plans of patients } \\
\text { easily at the patient's bed. This circumstance } \\
\text { prevents food waste, as the patients always } \\
\text { receive the food according to their needs. }\end{array}$ \\
\hline
\end{tabular}

Second, the sub-activities of the WM are described in detail. In the scope of this research, only the nurse rounding process is analyzed to impede complexity for the reader. Nurse Rounding is the process, in which a nurse visits their patients on a regular basis to ensure that the patient's vital signs, medications and other critical aspects of their care are under control. The rounding process is connected with the AIDET pattern [34] and is composed out of these eight steps:

1. A nurse receives an alert that a patient needs to be rounded.

2. The nurse walks to the patient's room.

3. The patient is acknowledged by the nurse

4. The nurse introduces themself and their task

5. The nurse executes their task, while they is explaining what they is doing and answers questions to the patient.

6. After the task is completed, the nurse logs into the bedside $\mathrm{PoC}$ device, using their fingerprint.

7. The nurse selects the nurse rounding survey and fills it with the requested information, regarding the patient's status

8. Eventually, the nurse logs out of the PoC bedside system and asks the patient if further help is required. Then they leave the room and move on to their next patient or task

The WM sub-activity of Nurse Rounding has a positive synergy effect with all goals, except "staff hours", which has a neutral synergy, and "bed occupancy rate", which has a negative synergy effect. Thus, it is likely that there exist contradictions regarding the bed occupancy. Nevertheless, Nurse Rounding shows the highest positive synergy effect in comparison to the other sub-activities and therefore is the most influential one of the whole system.

In the activity system of Nurse Rounding (see Figure 3), the patient is defined as the only object of the activity, although he or she could also transform into a subject while talking to the nurse [23]. This step

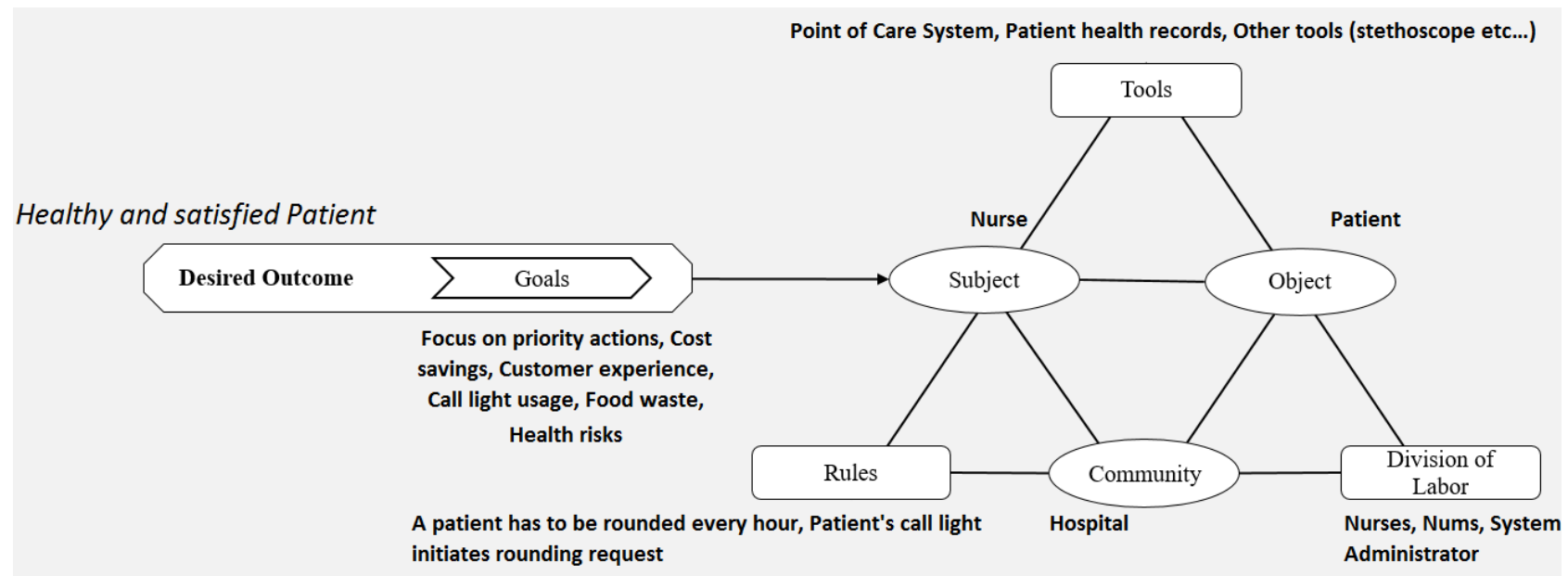

Figure 3: The activity system of Nurse Rounding 
was taken to simplify the context and to highlight the focus on the patient.

The nurse is the subject of the sub-activity system and interacts with the patient by the means of the PoC system. The nurse, therefore, has to comply these two rules: (1) a patient has to be rounded every 60 minutes; (2) a patient who calls assistance with their call light has to be rounded immediately.

The rules are prescribed by the community, which in this case is the non-for-profit hospital in Australia.

Within the scope of Nurse Rounding the division of labor consists out of nurses, who are responsible for the rounding itself, nums, who are the managing units and assign patients to their subordinates, and the system administrator, who takes care for the smooth operation of the PoC system.

\subsection{System Improvement}

Eventually, after describing the sub-activities in detail, contradictions have to be uncovered and resolved:

As a first step, all contradictions in the system are revealed and categorized according to their levels. A brief extract of the contradictions found in the subactivity system of Nurse Rounding can be seen in Table 5.

Table 5: Extract of found contradictions in the Nurse Rounding sub-activity system

\begin{tabular}{|l|l|}
\hline Level & Description \\
\hline component & $\begin{array}{l}\text { Contradiction in Tools: It is not clearly } \\
\text { shown in the PoC system whether a patient } \\
\text { pressed the call light or is due for hourly } \\
\text { rounding. }\end{array}$ \\
\hline $\begin{array}{l}\text { component } \\
\text { conter }\end{array}$ & $\begin{array}{l}\text { Contradiction between Subject-Tool-Object: } \\
\text { The nurse positions the PoC terminal } \\
\text { between themself and the patient. This error } \\
\text { decreases patient experience. }\end{array}$ \\
\hline $3-$ Intra & $\begin{array}{l}\text { Contradiction out of updating the system: } \\
\text { Nurses could have problems adapting to PoC } \\
\text { software updates because the system } \\
\text { administrator did not inform them about new } \\
\text { features or did not provide a necessary } \\
\text { educational workshop }\end{array}$ \\
\hline $\begin{array}{l}\text { activity } \\
\text { anter }\end{array}$ & $\begin{array}{l}\text { Contradiction between Nurse Rounding and } \\
\text { Room Ready: No specification on what } \\
\text { should happen when a room has to be } \\
\text { cleaned by a cleaner and at the same time } \\
\text { has to be rounded by a nurse. What happens } \\
\text { if a nurse enters the patient's room while the } \\
\text { room is occupied by the cleaner? (This } \\
\text { contradiction affects the "bed occupancy } \\
\text { rate" goal negatively) }\end{array}$ \\
\hline
\end{tabular}

After the contradictions are revealed and sorted according to their level, a general recommendation out of the TRIZ principle catalog [35] has to be found. In the case of our first contradiction (see Table 5), the segmentation principle was chosen. This principle considers that a problem can be solved by splitting the deficient component into independent parts or create a modular version of it [35].

It is defined that a call light request has higher priority than a necessary rounding visit due to the fact that a serious incident could have happened to the patient who called for help. In order to implement segmentation, the regular rounding and call light request should be displayed in different colors on the nurses' user interfaces, so that they can interpret the rounding priority.

Table 6 describes briefly how the other three contradictions were solved.

Table 6: Solutions for revealed contradictions

\begin{tabular}{|l|l|l|}
\hline Level & Principle & Implementation of Solution \\
\hline 2 & Training & $\begin{array}{l}\text { Nurses have to be trained how to use the } \\
\text { system properly and how to communicate to } \\
\text { the patient while completing the } \\
\text { questionnaire. }\end{array}$ \\
\hline 3 & $\begin{array}{l}\text { Gradual } \\
\text { transition }\end{array}$ & $\begin{array}{l}\text { Nurses can update their user interface } \\
\text { manually and read the changes and new } \\
\text { instructions when they have time for it. Until } \\
\text { then the system remains the same. }\end{array}$ \\
\hline 4 & Overload & $\begin{array}{l}\text { As a room cannot be occupied by a nurse and } \\
\text { a cleaning staff at the same time, new rules } \\
\text { and features at the PoC system have to be } \\
\text { implemented. E.g.: When staff is logged into } \\
\text { the PoC system at the patient's bed, the room } \\
\text { is set to "occupied". This status can be seen } \\
\text { on the entire station level. }\end{array}$ \\
\hline
\end{tabular}

\section{Discussion}

This study has revealed implications for theory and practice. From the theoretical perspective, it has been shown that the addition of new aspects to AT, such as the analysis of sub-activities and the emphasis on improvement, adds depth and richness to the resultant analyses and thereby helps to develop a complete understanding of the specific context and impact of introduced or existing tools into an activity system. The standardized documentation of goals offers advanced insights in the purpose of activities and, therefore, can help to uncover tensions which cannot be identified at first glance. Additionally, contradictions can be uncovered easily by having a look at the overall activity system, as well as its subactivity systems because the AT framework provides a much richer view on the activity than it Engeström's 
activity system does [17]. Ultimately, the recommendations by the means of TRIZ are a valuable extension to AT. TRIZ is applied straightforwardly, and the principles provide accurate indications for solving problems, respectively contradictions.

From the practical aspect, AT is suggested as a suitable framework to analyze sophisticated healthcare settings. Activity systems dialectically link material and social aspects and, thus, are perfect for healthcare, as clinicians frequently use technological tools to interact with their patients. In addition, AT provides another view on SCS in healthcare because social complexity can be depicted precisely. Albeit other modeling languages like Business Process Modelling and Notation illustrate processes in a more clearly arranged manner, AT can explain the social interactions behind the scenes. Moreover, defining the patient as the main object of the activity system emphasizes the human focus in healthcare. Thus, the researchers applying AT cannot easily digress to enhance or develop features which are not relevant for the patient's health.

This case study has shown that the framework is not only applicable for Computer Supported Cooperative Work (CSCW), for which it was intentionally created, but also for STS in healthcare. However, there became certain differences apparent between the both research fields (see Table 7).

First of all, we recognized that in CSCW technical components are in focus. In healthcare, it is the opposite. The patient and the clinicians are the main drivers of activity. The social factor is the most important.

Second, the application of the AT framework on a CSCW system [24] has shown that its goals mostly are related to quality attributes of software, such as reliability or accessibility of information. These criteria are also important in the healthcare context, but in contrast to $\mathrm{CSCW}$, they play a subordinate role. In healthcare, the goals always should be directed towards the needs of the patient.

\section{Table 7: Differences between CSCW and healthcare} systems

\begin{tabular}{|c|c|}
\hline CSCW systems & $\begin{array}{c}\text { Socio-technical systems in } \\
\text { Healthcare }\end{array}$ \\
\hline Technical features in focus & Patient in focus \\
\hline $\begin{array}{c}\text { Goals are mostly software } \\
\text { quality attributes }\end{array}$ & $\begin{array}{c}\text { Goals are mostly the } \\
\text { satisfaction and health of the } \\
\text { patient, as well as affordability } \\
\text { of health care }\end{array}$ \\
\hline
\end{tabular}

\section{Conclusion}

This exploratory study demonstrated the usefulness of an innovative AT framework with enhancements towards analysis and improvement of activities in a clinical setting. For this reason, it is proposed to other researchers in the field of healthcare as a rich lens to detect and resolve problems in their systems. Nevertheless, there is also a need for further research to provide confirmatory evidence about the applicability of the presented framework in other STS areas, like digital learning or merchandise. This will form the focus of our future work.

\section{References}

[1] OneView, "OneView Solutions," 2016. [Online]. Available:

http://www.oneviewhealthcare.com/solutions/.

[2] N. G. Leveson and C. S. Turner, "An investigation of the Therac-25 accidents," Computer (Long. Beach. Calif)., vol. 26, no. 7, pp. 18-41, 1993.

[3] J. Riechert, C. Durst, and N. Wickramasinghe, "The application of activity theory to explain collaborative technology use in healthcare: The case of a chemotherapy ordering system," in 49th Hawaii International Conference on System Sciences, \{HICSS\} 2016, Koloa, HI, USA, January 5-8, 2016, 2016, pp. 989-997.

[4] K. Kuutti, "Where Are the Ionians of User Experience Research?," in Proceedings of the 6th Nordic Conference on Human-Computer Interaction: Extending Boundaries, 2010, pp. 715718.

[5] A. Giddens, The constitution of society: outline of the theory of structuration. Cambridge Cambridgeshire: Polity Press, 1984.

[6] I. Craib, Anthony Giddens. London New York: Routledge, 1992.

[7] C. M. Nyandiere, F. Kamuzora, and I. A. Lukandu, "Application of Structuration Theory and Activity Theory in Enterprise Resources Planning Systems Implementation for Universities," Comput. Technol. Appl., vol. 3, pp. 385-394, 2012.

[8] M. R. Jones and H. Karsten, “Giddens's Structuration Theory and Information Systems Research," MIS Q., vol. 32, no. 1, pp. 127-157, 2008.

[9] B. Latour, Science in action : how to follow scientists and engineers through society. Cambridge, Mass: Harvard University Press, 1987. 
[10] Y. Engeström, Developmental work research : expanding activity theory in practice. Berlin: Lehmanns Media, 2005.

[11] R. Miettinen, Dialogue and Creativity: Activity Theory in the Study of Science, Technology and Innovations. Lehmanns, 2009.

[12] M. Korpela, A. Mursu, A. Soriyan, A. Eerola, H. Häkkinen, and M. Toivanen, "Information Systems Research and Development by Activity Analysis and Development: Dead Horse or the Next Wave?," in Information Systems Research: Relevant Theory and Informed Practice, vol. 143, Boston: Kluwer Academic Publishers, 2004, pp. 453-471.

[13] H. Allert and C. Richter, "Activity Systems and Context Working as Core Concepts in Modeling Socio-Technical Systems," Learning, no. January 2007, pp. 28-39, 2007.

[14] L. S. Vygotsky, "Mind in Society: Development of Higher Psychological Processes." Harvard University Press, Cambridge, p. 176, 1978.

[15] A. N. Leont'ev, Activity, Consciousness, and Personality. Englewood Cliffs, NJ: Prentice Hall, 1978.

[16] O. W. Bertelsen and S. Bødker, "Activity Theory," in HCI Models, Theories, and Frameworks, Elsevier, 2003, pp. 291-324.

[17] Y. Engeström, Learning by Expanding An ActivityTheoretical Approach to Developmental Research, 1. Edition. Helsinki: Orienta-Konsultit Oy, 1987.

[18] M. Korpela, "Activity analysis as a method for information systems development: General introduction and experiments from Nigeria and Finland," Scand. J. Inf. Syst., 2000.

[19] V. Kaptelinin and B. Nardi, Activity Theory in HCI: Fundaments and Reflections. Morgan \& Claypool, 2012.

[20] K. Kuutti, "Activity theory as a potential framework for human-computer interaction research," in Context and consciousness: activity theory and human-computer interaction, B. Nardi, Ed. Cambridge and London: MIT Press, 1996, pp. 1744.

[21] Y. Engestrom, "Expansive Learning at Work: toward an activity theoretical reconceptualization," J. Educ. Work, vol. 14, no. 1, pp. 133-156, 2001. principles of activity theory," in Activity Theory in HCI: Fundamentals and Reflections, 2012, pp. 1105.

[23] G. Z. Bedny, Application of Systemic-Structural Activity Theory to Design and Training. Boca Raton: CRC Press, 2014.

[24] S. Luber, "Activity Theory based System Design for $\mathrm{CSCW}$ in Innovation Management," Unpubl. Master's Thesis, 2016.

[25] G. S. Altshuller, The innovation algorithm: TRIZ, systematic innovation and technical creativity. 1999.

[26] N. Wickramasinghe and S. Goldberg, "Adaptive Mapping to Realisation Methodology to Facilitate Mobile Initiatives in Healthcare," Int. J. Mob. Commun., vol. 5, no. 3, pp. 300-318, 2007.

[27] Y. Engeström, "Activity theory as a framework for analyzing and redesigning work.," Ergonomics, vol. 43, no. 7, pp. 960-974, Jul. 2000.

[28] a Coleman and M. Coleman, "Activity Theory Framework: A Basis for E-Health Readiness Assessment in Health Institutions," J. Commun., vol. 4, no. 2, pp. 95-100, 2013.

[29] E. Ash, J.S., Berg, M., Coiera, "Some Unintended Consequences of Information Technology in Health Care : The Nature of Patient Care Information System-related Errors," J Am Med Inf. Assoc., vol. 11, pp. 104-112, 2004.

[30] D. W. Wright, "Improving Heart Failure Outcomes Through Interactive Patient Care," 2011. [Online]. Available:

http://www.getwellnetwork.com/sites/default/files/p df/heart-failure-whitepaper.pdf.

[31] R. Yin, Case Study Research, 5th Ed + Applications of Case Study Research, 3rd Ed. City: Sage Pubns, 2013.

[32] R. E. Boyatzis, Transforming qualitative information: Thematic analysis and code development. Sage, 1998.

[33] U. Flick, An introduction to qualitative research. Sage, 2009.

[34] J. Scott, "Utilizing AIDET and other tools to increase patient satisfaction scores.," Radiol. Manage., vol. 34, no. 3, 2012.

[35] G. Altshuller, L. Shulyak, and S. Rodman, 40 Principles: TRIZ keys to innovation, vol. 1. Technical Innovation Center, Inc., 1997. 